\title{
Altered gut microbiota associated with symptom severity in Schizophrenia
}

\author{
Shijia Li ${ }^{1,2}$, Min Zhuo ${ }^{1,2}$, Xia Huang ${ }^{1,2}$, Yuanyuan Huang ${ }^{2,3}$, Jing Zhou ${ }^{2,4}$, Dongsheng Xiong ${ }^{2,4}$, Jiahui Li $^{2,4}$, Ya Liu

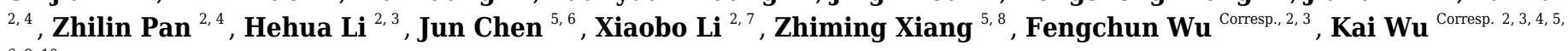 \\ $6,9,10$ \\ ${ }^{1}$ School of Biology and Biological Engineering, South China University of Technology, Guangzhou, Guangdong, China \\ 2 Guangdong Engineering Technology Research Center for Translational Medicine of Mental Disorders, Guangzhou, Guangdong, China \\ 3 Guangzhou Huiai Hospital, The Affiliated Brain Hospital of Guangzhou Medical University, Guangzhou, Guangdong, China \\ 4 \\ China \\ 5 Guangdong Engineering Technology Research Center for Diagnosis and Rehabilitation of Dementia, Guangzhou, Guangdong, China \\ 6 Key Laboratory of Biomedical Engineering of Guangdong Province, South China University of Technology, Guangzhou, Guangdong, China \\ 7 Department of Biomedical Engineering, New Jersey Institute of Technology, Newark, United States \\ 8 Department of Radiology, Panyu Central Hospital of Guangzhou, Guangzhou, Guangdong, China \\ 9 National Engineering Research Center for Tissue Restoration and Reconstruction, South China University of Technology, Guangzhou, Guangdong, China \\ 10 Department of Nuclear Medicine and Radiology/Institute of Development/Aging and Cancer, Tohoku University, Sendai, Japan \\ Corresponding Authors: Fengchun Wu, Kai Wu \\ Email address: 13580380071@163.com, kaiwu@scut.edu.cn
}

Background. The gut microbiome and microbiome-gut-brain (MGB) axis have been receiving increasing attention for their role in the regulation of mental behavior and possible biological basis of psychiatric disorders. With the advance of next-generation sequencing (NGS) technology, characterization of the gut microbiota in schizophrenia (SZ) patients can provide rich clues for the diagnosis and prevention of SZ.

Methods. In this study, we compared the differences in the fecal microbiota between 82 schizophrenia patients (SZs) and 80 demographically matched normal controls (NCs) by 16S rRNA sequencing and analyzed the correlations between altered gut microbiota and symptom severity.

Results. The alpha diversity showed no significant differences between the NC and SZ groups, but the beta diversity revealed significant community-level separation in microbiome composition between the two groups (pseudo- $F=3.337, p<0.001$, uncorrected). At the phylum level, relatively more Actinobacteria and less Firmicutes ( $p<0.05$, FDR corrected) were found in the SZ group. At the genus level, the relative abundances of Collinsella, Lactobacillus, Succinivibrio, Mogibacterium, Corynebacterium, undefined Ruminococcus and undefined Eubacterium were significantly increased, whereas the abundances of Adlercreutzia, Anaerostipes, Ruminococcus and Faecalibacterium were decreased in the SZ group compared to the NC group ( $p<0.05$, FDR corrected). We performed PICRUSt analysis and found that several metabolic pathways differed significantly between the two groups, including the Polyketide sugar unit biosynthesis, Valine, Leucine and Isoleucine biosynthesis, Pantothenate and CoA biosynthesis, C5-Branched dibasic acid metabolism, Phenylpropanoid biosynthesis, Ascorbate and aldarate metabolism, Nucleotide metabolism and Propanoate metabolism pathways ( $p<0.05$, FDR corrected). Among the SZ group, the abundance of Succinivibrio was positively correlated with the total PANSS scores $(r=0.24, p<0.05$, uncorrected) as well as the general PANSS scores $(r=0.22, p<0.05$, uncorrected); Corynebacterium was negatively related to the negative scores 
of PANSS ( $r=0.22, p<0.05$, uncorrected).

Conclusions. Our findings provided evidence of altered gut microbial composition in SZ group. In addition, we found that Succinvibrio and Corynebacterium were associated with the severity of symptoms for the first time, which may provide some new biomarkers for the diagnosis of SZ. 


\section{Altered gut microbiota associated with symptom severity in Schizophrenia}

Shijia Li ${ }^{1,2}$, Min Zhuo ${ }^{1,2}$, Xia Huang ${ }^{1,2}$, Yuanyuan Huang ${ }^{2,3}$, Jing Zhou ${ }^{2,4}$, Dongsheng Xiong ${ }^{2,4}$, Jiahui $\mathrm{Li}^{2,4}$, Ya Liu ${ }^{2,4}$, Zhilin Pan ${ }^{2,4}$, Hehua $\mathrm{Li}^{2,3}$, Jun Chen ${ }^{5,6}$, Xiaobo Li ${ }^{2,7}$, Zhiming Xiang ${ }^{5,8}$, Fengchun $\mathrm{Wu}^{2,3}$, Kai $\mathrm{Wu}^{2,3,4,5,6,9,10}$

1. School of Biology and Biological Engineering, South China University of Technology, Guangzhou, Guangdong, China

2. Guangdong Engineering Technology Research Center for Translational Medicine of Mental Disorders, Guangzhou, Guangdong, China

3. The Affiliated Brain Hospital of Guangzhou Medical University, Guangzhou Huiai Hospital, Guangzhou, Guangdong, China

4. Department of Biomedical Engineering, School of Material Science and Engineering, South China University of Technology, Guangzhou, Guangdong, China

5. Guangdong Engineering Technology Research Center for Diagnosis and Rehabilitation of Dementia, Guangzhou, Guangdong, China

6. Key Laboratory of Biomedical Engineering of Guangdong Province, South China University of Technology, Guangzhou, Guangdong, China

7. Department of Biomedical Engineering, New Jersey Institute of Technology, Newark, United States

8. Department of Radiology, Panyu Central Hospital of Guangzhou, Guangzhou, Guangdong, China

9. National Engineering Research Center for Tissue Restoration and Reconstruction, South China University of Technology, Guangzhou, Guangdong, China

10. Department of Nuclear Medicine and Radiology, Institute of Development, Aging and Cancer, Tohoku University, Sendai, Japan

Corresponding author: 
E-mail address: kaiwu@scut.edu.cn, 13580380071@163.com

32

\section{Abstract}

Background. The gut microbiome and microbiome-gut-brain (MGB) axis have been receiving increasing attention for their role in the regulation of mental behavior and possible biological basis of psychiatric disorders. With the advance of next-generation sequencing (NGS) technology, characterization of the gut microbiota in schizophrenia (SZ) patients can provide rich clues for the diagnosis and prevention of SZ.

Methods. In this study, we compared the differences in the fecal microbiota between 82 schizophrenia patients (SZs) and 80 demographically matched normal controls (NCs) by $16 \mathrm{~S}$ rRNA sequencing and analyzed the correlations between altered gut microbiota and symptom severity.

Results. The alpha diversity showed no significant differences between the NC and SZ groups, but the beta diversity revealed significant community-level separation in microbiome composition between the two groups (pseudo-F $=3.337, \mathrm{p}<0.001$, uncorrected). At the phylum level, relatively more Actinobacteria and less Firmicutes ( $p<0.05$, FDR corrected) were found in the SZ group. At the genus level, the relative abundances of Collinsella, Lactobacillus, Succinivibrio, Mogibacterium, Corynebacterium, undefined Ruminococcus and undefined Eubacterium were significantly increased, whereas the abundances of Adlercreutzia, Anaerostipes, Ruminococcus and Faecalibacterium were decreased in the SZ group compared to the NC group ( $\mathrm{p}<0.05, \mathrm{FDR}$ corrected). We performed PICRUSt analysis and found that several metabolic pathways differed significantly between the two groups, including the Polyketide sugar unit biosynthesis, Valine, Leucine and Isoleucine biosynthesis, Pantothenate and CoA biosynthesis, C5-Branched dibasic acid metabolism, Phenylpropanoid biosynthesis, Ascorbate and aldarate metabolism, Nucleotide metabolism and Propanoate metabolism pathways $(\mathrm{p}<0.05$, FDR corrected). Among the SZ group, the abundance of Succinivibrio was positively correlated with the total PANSS scores $(\mathrm{r}=$ 
56

57

58

$0.24, \mathrm{p}<0.05$, uncorrected) as well as the general PANSS scores $(\mathrm{r}=0.22, \mathrm{p}<0.05$, uncorrected $)$; Corynebacterium was negatively related to the negative scores of PANSS $(\mathrm{r}=0.22, \mathrm{p}<0.05$, uncorrected).

Conclusions. Our findings provided evidence of altered gut microbial composition in SZ group. In addition, we found that Succinvibrio and Corynebacterium were associated with the severity of symptoms for the first time, which may provide some new biomarkers for the diagnosis of SZ.

\section{Introduction}

Schizophrenia (SZ) is a complex, chronic psychiatric disorder with a heterogeneous genetic and neurobiological background(Bang et al. 2014; Hoekert et al. 2007; McGlashan \& Fenton 1992). Treatments for schizophrenia are available, but their effectiveness is poor for many patients(Higuchi et al. 2019; Kraus et al. 2006). To acquire better therapeutic results, we need to completely understand the pathophysiology of SZ. Previously, researchers have focused on analyzing the human genome(Ripke et al. 2011) and environmental risk factors(Brown et al. 2002; Cannon et al. ; Cantor-Graae \& Selten 2005; Mulvany et al. 2001; Sara et al. 2014; Stilo et al. 2017; van Os et al. 2004; Varese et al. 2012) to determine the pathogenesis of SZ. However, the identified associations only account for some of the variance in $\mathrm{SZ}(\mathrm{Wu}$ et al. 2019). Recently, interest in researching the effect of gut microbiota on host physiology and pathology has increased rapidly. The variations in the composition of the gut microbiota influence inflammatory and metabolic pathways across a number of diseases, such as inflammatory bowel disease(Huttenhower et al. 2014), obesity and metabolic diseases(Bouter et al. 2017; Hartstra et al. 2015), cancer(Schwabe \& Jobin 2013), and chronic pulmonary diseases(Shukla et al. 2017). Converging evidence also suggests that the gut microbiota communicates with the central nervous system bidirectionally through the microbiome-gut-brain (MGB) axis and thereby influences brain function and behavior(Cryan \& Dinan 2012; Desbonnet et al. 2014; Hsiao et al. 2013; Sampson et al. 2016). A dysregulated MGB axis has been reported in many neuropsychiatric disorders 
82 including bipolar disorder(Hu et al. 2019), major depression disorder(Zheng et al. 2016), 83 Alzheimer's disease(Cattaneo et al. 2017), Parkinson's disease(Caputi \& Giron 2018), and 84 autism(Tomova et al. 2015).

85 Recently, a few articles have focused on the role of the MGB axis in SZ. Epidemiological studies have shown that prenatal microbial infections appear to increase the risk of SZ in offspring(Babulas et al. 2006). Additionally, SZ often superinduces gut and digestive disturbances or intestinal inflammation with a high prevalence(Severance et al. 2012; Severance et al. 2015; Sherwin et al. 2016; Yolken et al. 2015). Some clinical studies indicate potential associations between a disturbed gut microbiome and SZ(Lv et al.). Castro-Nallar et al sequenced microbes in the oropharynx of patients who have SZ and found a difference between the SZs and normal controls (NCs)(Castro-Nallar et al. 2015), which further indicated that the host microbiome have an impact on host's health. The gut microbiota and its metabolites are critical in promoting neurodevelopment by modulating important agents, such as neurotrophin and neurotransmitters. Fecal microbiota transplantation (FMT) showed that germ-free mice that received SZ microbiome fecal transplants displayed SZ-relevant behaviors similar to SZ mouse models(Zheng et al. 2019). 
109 brain(Louveau et al. 2018), lower levels of SCFA induced by decreased colonic bacteria can 110 damage the intestinal barrier and the BBB, altering microlia vulnerability and morphology and 111 activating immune responses and neuroinflammation. In conclusion, disturbances in the gut 112 microbiota may cause microglia-mediated neuroinflammation and damage to neurons, synapses, 113 and connectivity between brain regions. These disturbances are a possible mechanism for the 114 etiopathology of schizophrenia.

115 Previous studies discovered that the abundance of some bacteria in the gut of SZs is quite 116 different from that in the gut of normal controls. One of these studies found that at the phylum 117 level, Proteobacteria was significantly increased in SZs; the genera Succinivibrio, Megasphaera, 118 Collinsella, Clostridium, Klebsiella and Methanobrevibacter were significantly higher, whereas 119 Blautia, Coprococcus, and Roseburia were decreased compared to NCs, and receiver operating 120 characteristic curve analysis demonstrated that 12 microbiota could be used to distinguish SZs from NCs(Shen et al. 2018). Another study based on the metagenomic analysis of gut microbiota showed that the numbers of Lactobacillus group bacteria were elevated in first-episode SZs and significantly correlated with severity(Schwarz et al. 2018). In addition, the investigation of the gut microbiome in US-based patients with chronic schizophrenia revealed that the phylum Proteobacteria was relatively decreased in SZs, and at the genus level, Anaerococcus was relatively increased in SZs, while Haemophilus, Sutterella and Clostridium were decreased(Nguyen et al. 2018), and increased negative symptoms were associated with decreased abundance of family Ruminococcaceae and greater severity of depressive symptoms was correlated with greater abundance of genus Bacteroides. In these studies, the taxonomies of altered bacteria in SZs are inconsistent, and the correlation between altered gut microbiota and symptom severity are not fully understood. The inconsistencies might be due to 1) the small sample size of these studies; 2) various factors, such as region, diet, environment, etc.(Huttenhower et al. 2012); 3) subjects with other mental disorders.

The objective of this study was to characterize the gut microbiome in SZs and preliminary analyze the correlation between the altered gut microbiota and the severity of symptoms. We 
136

137

138

139

140

141

142

143

144

145

146

147

148

149

150

151

152

153

154

155

156

157

158

159

160

excluded individuals with any chronic disease that may affect the stability of the gut microbiota, including intestinal inflammation, Constipation, diarrhea and diabetes; expanded the sample size; and controlled the drug use of the NCs to eliminate possible bias. We hypothesized that 1) gut microbial composition might differ between the SZ and NC groups and 2) the altered gut microbiota in SZs might significantly correlate with symptom severity.

\section{Materials \& Methods}

\section{Participants}

A total of 162 subjects were collected in this study from September 2017 to February 2019, including 82 SZs and 80 NCs. The SZs were recruited from Guangzhou Huiai Hospital and were diagnosed by trained and experienced clinical psychiatrists according to the structured clinical interview according to the Diagnostic and Statistical Manual of Mental Disorder-IV-Text Revision (DSM-IV-TR) (SCID) criteria(Wu et al. 2018); The psychiatric symptoms were steady > 2 weeks; the Positive and Negative Syndrome Scale (PANSS) evaluated the rate of change $\leq 20 \%$ in 2 weeks and the total score of PANSS $\geq 30.75$ patients were treated with antipsychotics at the time of the study (Supplemental file 1). The exclusion criteria for patients included 1) any other psychiatric Axis I disorder meeting DSM-IV criteria, including schizoaffective disorder, mental retardation, major depressive disorder, bipolar, delirium, dementia, memory disorder, and other cognitive disorders; 2) constipation, diarrhea, diabetes, hypertension, heart disease, thyroid diseases or any somatic diseases; 3) a history of epilepsy, except for febrile convulsions; 4) a history of having received electroconvulsive therapy in the past six months; 5) lactating, pregnant, or planning to become pregnant; 6) alcohol dependence or 7) noncompliant drug administration or a lack of legal guardians.

NCs were recruited in Guangzhou and surrounding areas through multiple methods, including recruitment flyers in the community, internet ads and word-of-mouth. The age, sex and nationality of all NCs were matched with the SZs. The inclusion criteria of NCs were as follows: 1) the Han 
161

162

163

164

165

166

167

168

169

170

171

172

173

174

175

176

177

178

179

180

181

182

183

184

185

186

nationality, no special religious beliefs; 2) 18-65 years; 3) absence of antibiotic intake for the last 3 months and with no diarrhea at present; 4) absence of any chronic disease that may affect the stability of gut microbiota; 5) BMI $18-30 \mathrm{~kg} / \mathrm{m} 2$; 6) absence of any major gastrointestinal tract surgery within 5 years; and 7) absence of any head surgery and no mental disorders.

All participants signed the information consent form, indicating their agreement. The sample collection and the protocol of analysis were approved by Guangzhou Brain Hospital. A questionnaire was conducted among all subjects to collect general information, including age, sex, height, weight, years of education, history of taking medicine, and history of smoking and drinking.

2. Fecal sample collection and $16 \mathrm{~S}$ ribosome RNA sequencing

Fresh fecal samples were obtained from participants, and all of the samples were stored at -80 ${ }^{\circ} \mathrm{C}$ until DNA extraction. A total of $200 \mathrm{mg}$ of each fecal sample was used for DNA extraction.

Community DNA was extracted under the manual of the MOBIO PowerSoil ${ }^{\circledR}$ DNA Isolation Kit 12888-100 protocol. Prior to sequencing, the DNA was stored in Tris-EDTA buffer solution at $-80{ }^{\circ} \mathrm{C}$. To enable amplification of the $\mathrm{V} 4$ region of the $16 \mathrm{~S}$ rRNA gene and add barcode sequences, unique fusion primers were designed based on the universal primer set $515 \mathrm{~F}$ ( $5^{\prime}-$ GTGYCAGCMGCCGCGGTAA-3') and 806R (5'-GGACTACNVGGGTWTCTAAT-3') along with barcode sequences. PCR mixtures in $50 \mu \mathrm{L}$ reaction volumes contained $1 \mu \mathrm{L}$ of each forward and reverse primer $(10 \mu \mathrm{M}), 1 \mu \mathrm{L}$ of Easy Pfu DNA Polymerase $(2.5 \mathrm{U} / \mu \mathrm{L}), 4 \mu \mathrm{L}$ of dNTPs $(2.5$ $\mathrm{mM}), 1 \mu \mathrm{L}$ of template DNA, $1 \mu \mathrm{L}$ of double distilled water, and $5 \mu \mathrm{L}$ of $10 \times$ EasyPfu Buffer. Thermal cycling consisted of an initial denaturation step at $95{ }^{\circ} \mathrm{C}$ for $5 \mathrm{~min}$, followed by 30 cycles of denaturation at $94{ }^{\circ} \mathrm{C}$ for $30 \mathrm{~s}$, annealing at $60^{\circ} \mathrm{C}$ for $30 \mathrm{~s}$, and extension at $72{ }^{\circ} \mathrm{C}$ for $40 \mathrm{~s}$, with a final extension step at $72{ }^{\circ} \mathrm{C}$ for $4 \mathrm{~min}$. Amplicons from each sample were run on an agarose gel. The expected band size for 515f-806r is approximately 300-350 bp. Amplicons were quantified with Quant-iT PicoGreen dsDNA Assay Kit (ThermoFisher/Invitrogen cat. no. P11496) following the manufacturer's instructions. According to the manufacturer's instructions, the amplicon 
187 libraries for high-throughput sequencing on the Illumina MiSeq platform were combined in equal amounts and subsequently quantified (KAPA Library Quantification Kit KK4824).

The raw sequences were processed to concatenate reads into tags according to the overlapping relationship by using QIIME2(Bolyen et al. 2019). The DADA2 algorithm was performed to demultiplex raw sequences and identify microbial features(Callahan et al. 2016). The output features were rarefied to 13581 sequences per sample, which was the lowest value in the dataset. The microbial community structure was characterized using measures of alpha-diversity (withinsample) and beta-diversity (between-samples). The alpha-diversity indices we selected were Evenness, Faith's Phylogenetic Diversity, Observed Species and Shannon, which represent the evenness and richness of taxa within a single sample, and the differences in diversity between groups were calculated using the nonparametric Kruskal-Wallis $\mathrm{H}$ test in QIIME2. The betadiversity indicates differences in taxa composition between groups, which were calculated using Bray-Curtis dissimilarity. Principal coordinate analysis (PCoA) based on the Bray-Curtis distances matrix was used for visualizing sample relationships, and PERMANOVA with 999 permutations was used to assess the statistical significance of beta-diversity distances between groups. Output matrices were ordinated and visualized using the vegan package from R(Oksanen et al. 2019). We used a pretrained Naïve Bayes classifier for taxonomic analysis. This classifier was trained on the Greengenes database (13.8)(DeSantis et al. 2006), and all differential abundances at different taxonomic levels were tested using the Mann-Whitney U test. Linear discriminant analysis (LDA) effect size (LEfSe) was used to identify different markers, an alpha $=0.01$ was used in the factorial Kruskal-Wallis test among groups, and the log value for the LDA score was set to $>2$. To determine the association between differential abundance at the genus level and clinical characteristics, we further calculated the residuals of relative abundance of those taxa with significant group differences, controlling for age, sex and years of education, by the 'vglm' function in the VGAM package(Yee 2007). Pearson's correlations were then calculated between 
213 the residuals of relative abundance of those taxa from patients and the PANSS scores.

214 Significances of all tests were set as $\mathrm{p}<0.05$, or FDR corrected $\mathrm{p}<0.05$ (two side). To obtain

215 insight into the possible functional pathways that differ between SZs and NCs, we used

216 PICRUSt(Langille et al. 2013) to calculate contributions of various features to known biological

217 pathways based on KEGG orthology groups (KOs) using the Kyoto Encyclopedia of Genes and

218 Genomes (KEGG) databases(Ogata et al. 2000).

219

220

\section{Results}

221

222

223

224

225

226

227

228

229

230

231

232

233

234

235

236

\section{Clinical data}

A total of $82 \mathrm{SZs}$ and $80 \mathrm{NCs}$ were recruited according to the inclusion criteria. Demographic and clinical characteristics of the groups are presented in Table 1. The SZ and NC groups did not differ in age $(p=0.60$, uncorrected $)$ or $\operatorname{sex}(p=0.35$, uncorrected $)$. The years of education $(p=$ $2.04 \times 10^{-6}$, uncorrected) and BMI ( $\mathrm{p}=0.01$, uncorrected) of the SZ group were lower than those of the NC group. The ratio of tobacco using was higher in the SZ group than in the NC group $(\mathrm{p}=$ 0.01 , uncorrected), while alcohol intake was lower $\left(\mathrm{p}=3.36 \times 10^{-8}\right.$, uncorrected). Comparing highdensity lipoprotein cholesterol (HDL-C), low-density lipoprotein cholesterol (LDL-C) and glucose in serum, the SZ group showed lower values of HDL-C $\left(\mathrm{p}=1.08 \times 10^{-4}\right.$, uncorrected $)$, LDL-C $(\mathrm{p}=$ $6.35 \times 10^{-6}$, uncorrected) and glucose ( $\mathrm{p}=1.68 \times 10^{-7}$, uncorrected) compared to the NC group. In addition, the SZ group showed lower values of total cholesterol (TC) $\left(\mathrm{p}=4.95 \times 10^{-15}\right.$, uncorrected) and triglyceride $(\mathrm{TG})(\mathrm{p}=0.01$, uncorrected $)$.

\section{Sequencing data}

We obtained 7456515 raw sequences from all subjects $(n=162)$, ranging from 15449 to 95651 . After quality filtering and removal of the chimeric sequences, we obtained 6817960 high quality reads for further analysis of bacterial composition, ranging from 13581 to 90203 and with a mean 
237

238

239

240

241

242

243

244

245

246

247

248

249

250

251

252

253

254

255

256

257

258

259

260

261

262

of 42086.2 reads. After clustering all the high-quality reads, a total of 2031 features were obtained, and the frequency per feature ranged from 2 to 533200, with a mean of 3356.9 .

Then, alpha-diversity and beta-diversity calculations were performed. The results showed no significant difference in all alpha-diversity indices between the two groups (Table S1). Analysis of beta-diversity indices using Bray-Curtis dissimilarity revealed significant community-level separation between the SZ and NC groups (pseudo-F $=3.337, \mathrm{p}=0.001$, uncorrected). PCoA of Bray-Curtis distances showed that the SZ and NC groups formed distinct clusters (Fig. 1). Additionally, the microbiota of the NC group displayed significantly tighter clustering compared to the SZ group, with average Bray-Curtis distances of $0.79 \pm 0.05$ vs. $0.81 \pm 0.06(\mathrm{p}=0.038$, uncorrected).

3. Bacterial taxonomic compositions and identifications of biomarkers

The predominant bacteria at the phylum level were the same between the SZ and NC groups (Fig. 2B), including Firmicutes, Bacteroidetes, Actinobacteria, Proteobacteria and Verrucomicrobia. When comparing the relative abundances of the phyla of the two groups, Actinobacteria was significantly higher in the SZ group than in the NC group (p $=0.0046$, FDR corrected), whereas Firmicutes was lower ( $\mathrm{p}=0.026$, FDR corrected) (Fig. 2B).

At the genus level, the most abundant genus in the SZs was Faecalibacterium, followed by Megamonas, Prevotella, Ruminococcus and Blautia (Fig. 2A). The bacteria in the NCs were mainly assigned to Faecalibacterium, Megamonas, Gemmiger, Roseburia and Bacteroides. Genera with different relative abundances between the two groups are shown in Fig. 2A. Compared to the NC group, the relative abundance of undefined Ruminococcus $(\mathrm{p}=0.0052$, FDR corrected), Collinsella $\left(\mathrm{p}=0.00094\right.$, FDR corrected), undefined Eubacterium $\left(\mathrm{p}=8.05 \times 10^{-6}\right.$, FDR corrected), Lactobacillus( $\mathrm{p}=0.0148$, FDR corrected $),$ Succinivibrio $(\mathrm{p}=0.0148$, FDR corrected $)$, $\operatorname{Mogibacterium}(\mathrm{p}=0.0148$, FDR corrected $)$ and Corynebacterium( $\mathrm{p}=0.0413$, FDR corrected $)$ were significantly higher in the SZ group. However, Adlercreutzia(p $=0.0148$, FDR corrected), Anaerostipes( $\mathrm{p}=0.0025$, FDR corrected $),$ Ruminococcus $(\mathrm{p}=0.0083$, FDR corrected $)$ and 
263

264

265

266

267

268

269

270

271

272

273

274

275

276

277

278

279

280

281

282

283

284

285

286

287

Faecalibacterium $(\mathrm{p}=0.0223$, FDR corrected $)$ were higher in the NC group.

Application of the LefSe method identified a total of 41 features with significantly different abundances between the SZ and NC groups ( $\mathrm{p}<0.01$, uncorrected, LDA score $>2)$ (Fig. 3B). At the phylum level, the NC group was enriched with Firmicutes, while Actinobacteria was enriched in the SZ group $(\mathrm{p}<0.01$, uncorrected, LDA score $>2)$. We also observed that the NC group was differentially enriched with the genera Anaerostipes, Faecalibacterium, Adlercreutzia, Butyricimonas $(\mathrm{p}<0.01$, uncorrected, LDA score $>2)$, whereas the SZ group was enriched with Lactobacillus, Mogibacterium, Bulleidia, Eubacterium, Succinivibrio, Corynebacterium, Collinsella and Prevotella ( $\mathrm{p}<0.01$, uncorrected, LDA score $>2$ ) (Fig. 3A).

\section{Functional properties predicted by PICRUSt}

We performed PICRUSt analysis to predict the genetic potentials of the fecal microbiota metagenome based on 16S rRNA sequences. PICRUSt predicted metagenome content to Level 3 KOs and identified 328 functional pathways belonging to different Level $1 \mathrm{KOs}$, including 19 Cellular Processes, 28 Environmental Information Processing, 28 Genetic Information Processing, 40 Human Diseases, 146 Metabolism, 40 Organismal Systems and 40 Unclassified pathways (Data S1). We identified 19 significantly different functional pathways (Fig. 4, p < 0.05, FDR corrected). We found that varieties of biosynthesis and metabolism pathways were enriched in the NC group, such as Polyketide sugar unit biosynthesis, Valine, Leucine and Isoleucine biosynthesis, Pantothenate and CoA biosynthesis, C5-Branched dibasic acid metabolism and Phenylpropanoid biosynthesis. While Ascorbate and aldarate metabolism, Nucleotide metabolism and Propanoate metabolism pathways were enriched in the SZ group.

5. Relationship with clinical characteristics

We analyzed the relationship between 11 genera altered in the SZs and the PANSS scores. Greater severity of schizophrenia symptoms was positively correlated with the abundance of the genus Succinivibrio (total score, $\mathrm{r}=0.24, \mathrm{p}=0.032$, uncorrected; general score, $\mathrm{r}=0.22, \mathrm{p}=0.046$, 
288

289

290

291

292

uncorrected). While increased negative symptoms were negatively associated with the abundance of the genus Corynebacterium (negative score, $r=-0.22, p=0.044$, uncorrected). The results of the relationship between the 11 genera and the severity of symptoms are shown in Fig. 5 .

\section{Discussion}

To the best of our knowledge, this study is the first to indicate that altered gut microbiota is significantly correlated with symptom severity in SZs from South China. Consistent with previous studies, our results demonstrate that the SZs showed altered gut microbiome composition, including 2 phyla and 11 genera(De Filippo et al. 2010; Huttenhower et al. 2012; Nam et al. 2011; Zhang et al. 2015). Importantly, Succinivibrio was more abundant in SZs and correlated positively with the severity of symptoms. In contrast, Corynebacterium was more highly represented in SZs and negatively associated with the severity of negative symptoms, which may suggest that a greater abundance of Corynebacterium in SZs could remit the symptoms of blunted affect, poverty of speech and loss of drive. Thus, we speculated that an altered gut microbiome profile contributes to the pathogenesis and remission of SZ. Interestingly, Succinivibrio was detected in the SZs but not in the NCs, which may further suggest that Succinivibrio plays an important role in the development of SZ. In addition, we found that Lactobacillus was significantly higher in SZs. Schwarz et al.(Schwarz et al. 2018) found that the abundance of Lactobacillus was significantly increased in first episode SZ and was positively correlated with the severity of symptoms. However, the correlation between Lactobacillus and symptom severity was not significant in this study. One possible reason was the drug use of the subjects included in this study.

Second-generation antipsychotics (SGAs) have been used successfully for the treatment of SZ(Skonieczna-Żydecka et al. 2019), risperidone (RIS) and olanzapine (OLZ) are the most frequently prescribed atypical SGAs(Hálfdánarson et al. 2017). However, long-term SGA treatment can cause health consequences including significant weight gain and hypertriglyceridaemia(Chintoh et al. 2009; De Hert et al. 2011; Galling \& Correll 2015). In this 
314

315

316

317

318

319

320

321

322

323

324

325

326

327

328

329

330

331

332

333

334

335

336

337

338

339

340

study, 91\% SZs was treated with antipsychotics (Data S2). Our results showed that BMI and TG of SZs were significantly higher than that Of NCs, which was consistent with previous studies. Karolina et al. concluded that metabolic disturbances during SGA treatment may be the consequence, at least in part, of gut dysbiosis(Skonieczna-Żydecka et al. 2019). In addition, we were surprised to find that the TC in the NC group was significantly higher than that in the SZ group, which we speculated might be due to the higher alcohol intake ratio in the NC group (30 vs $3, p=3.36 \times 10^{-8}$, uncorrected). An expanding body of evidence supports the notion that microbes can metabolise drugs and vice versa drugs can modify the gut microbiota composition. Bahr et al. (Bahr et al. 2015) identified the Bacteroidetes/Firmicutes ratio was significantly lowered in chronic and short-term RIS users. Morgan et al.(Morgan et al. 2014) revealed decreased alpha diversity, lower abundance of class Bacteroidia, and increased abundances of Erysipelotrichia, Actinobacteria and Gammaproteobacteria in female mice treated with OLZ. However, Kao et al.(Kao et al. 2018) demonstrated no significant effects of OLZ on gut microbiota in female rats. Justyna et al.(Pełka-Wysiecka et al. 2019) further explored the gut microbiota and OLZ treatment interactions, they classified the included SZs as responders and non-responders, there were no differences in gut microbiota compositions at phyla and genus levels. Hence, the effect of antipsychotics between gut microbiota needs further study.

There are a number of bidirectional signaling pathways by which the gut microbiota, acting via the brain-gut axis, can impact the brain(Kelly et al. 2017), including amino acid metabolism(Saleem et al. 2017), immune system modulation(Erny et al. 2015), hypothalamicpituitary-adrenal (HPA) axis(Mudd et al. 2017), vagus nerve(Bravo et al. 2011) and the production of bacterial metabolites, such as short-chain fatty acids (SCFA)(Tan et al. 2014). In this study, PICRUSt results showed multiple SCFAs and amino acid metabolic pathways that were significantly enriched between the two groups (Figure S1). SCFAs are the main metabolites of the gut microbiota(Wong et al. 2006); SCFAs can enter the central nervous system through the bloodbrain barrier(De Vadder et al. 2014), stimulating TNF in the body(Morris et al. 2017), activating microglia(Sampson et al. 2016), interfering with membrane metabolism of cells, and thus may 
341 induce schizophrenia. He et al.(He et al. 2018) reported that an increased relative abundance of

342 Lactobacillus in SZs can stimulate TNF production. Based on this, it is speculated that the

343 increased Lactobacillus may induce changes in inflammatory factors and induce schizophrenia.

344 Amino acids and derivatives participate in the biosynthesis and downstream effects of numerous

345 neurotransmitters(Cao et al. 2018). We found that the tryptophan metabolism was significantly

346 enriched in the fecal microbiome of SZs. Zhu et al.(Zhu et al. 2019) reported that the tryptophan

347 level in mice transplanted with SZ fecal microbiota was significantly lower than that in NC mice,

348 and they also found that tryptophan biosynthesis was significantly enriched in the fecal 349 microbiome of NC mice by shot-gun metagenomic sequencing. Tryptophan is an important source 350 of 5-hydroxytryptamine (5-HT). Tryptophan and kynurenine can cross the blood-brain barrier and 351 have a significant effect on the metabolism of neurotransmitters(Agus et al. 2018). Above all, these 352 investigations suggested that gut microbiota may profoundly affect the amino acid metabolism 353 pathway and neurotransmitter levels in schizophrenia patients.

354 Several methodological issues need to be addressed. First, we did not control the effect of 355 antipsychotic therapy on the gut microbiota due to the lack of data. The form of clinical information will be modified and the data of antipsychotic will be collected. Besides, we plan to recruit patients of first-episode schizophrenia in the future study. Second, in this preliminary study, we adopted the method of $16 \mathrm{~S}$ rRNA gene sequencing, which has a low phylogenetic power at the species level. According to the findings of this study, we have selected the specific subjects and have applied the metagenomic analysis in the next study. Third, the BMI of the part of subjects and the diet information of all subjects were lacked in this study. Further investigations will include all these data.

\section{Conclusions}

In conclusion, our findings provide evidence of altered gut microbial composition in patients who have SZ. In addition, we found that Succinivibrio and Corynebacterium were associated with the severity of symptoms for the first time, which may provide some new biomarkers for the 
diagnosis of SZ.

368

\section{Acknowledgements}

370

371

372

373

374

375

376

377

378

379

380

381

382

383

384

The authors would like to thank the editor as well as the three reviewers for their valuable suggestions and comments that helped to significantly improve the manuscript. We would also like to thank all the volunteers from the Affiliated Brain Hospital of Guangzhou Medical University and South China University of Technology. This work was supported by the National Natural Science Foundation of China (31771074, 81802230), the Guangdong Key Project in "Development of new tools for diagnosis and treatment of Autism" (2018B030335001), the Science and Technology Program of Guangzhou (201704020168, 201704020113, 201807010064, 201803010100, 201903010032). The authors thank American Journal Experts (http://www.journalexperts. com/) for English editing and proofreading.

\section{Reference}

Agus A, Planchais J, and Sokol H. 2018. Gut Microbiota Regulation of Tryptophan Metabolism in Health and Disease. Cell Host Microbe 23:716-724. 10.1016/j.chom.2018.05.003

Babulas V, Factor-Litvak P, Goetz R, Schaefer CA, and Brown AS. 2006. Prenatal Exposure to Maternal Genital and Reproductive Infections and Adult Schizophrenia. American Journal of Psychiatry 163:927-929. 10.1176/ajp.2006.163.5.927

Bahr SM, Tyler BC, Wooldridge N, Butcher BD, Burns TL, Teesch LM, Oltman CL, Azcarate-Peril MA, Kirby JR, and Calarge CA. 2015. Use of the second-generation antipsychotic, risperidone, and secondary weight gain are associated with an altered gut microbiota in children. Transl Psychiatry 5:e652. 10.1038/tp.2015.135

Bang M, Kim KR, Song YY, Baek S, Lee E, and An SK. 2014. Neurocognitive impairments in individuals at ultrahigh risk for psychosis: Who will really convert? Australian \& New Zealand Journal of Psychiatry 49:462470. $10.1177 / 0004867414561527$

Bolyen E, Rideout JR, Dillon MR, Bokulich NA, Abnet CC, Al-Ghalith GA, Alexander H, Alm EJ, Arumugam M, Asnicar F, Bai Y, Bisanz JE, Bittinger K, Brejnrod A, Brislawn CJ, Brown CT, Callahan BJ, CaraballoRodríguez AM, Chase J, Cope EK, Da Silva R, Diener C, Dorrestein PC, Douglas GM, Durall DM, Duvallet C, Edwardson CF, Ernst M, Estaki M, Fouquier J, Gauglitz JM, Gibbons SM, Gibson DL, Gonzalez A, Gorlick K, Guo J, Hillmann B, Holmes S, Holste H, Huttenhower C, Huttley GA, Janssen S, Jarmusch AK, 
Jiang L, Kaehler BD, Kang KB, Keefe CR, Keim P, Kelley ST, Knights D, Koester I, Kosciolek T, Kreps J, Langille MGI, Lee J, Ley R, Liu Y-X, Loftfield E, Lozupone C, Maher M, Marotz C, Martin BD, McDonald D, McIver LJ, Melnik AV, Metcalf JL, Morgan SC, Morton JT, Naimey AT, Navas-Molina JA, Nothias LF, Orchanian SB, Pearson T, Peoples SL, Petras D, Preuss ML, Pruesse E, Rasmussen LB, Rivers A, Robeson MS, Rosenthal P, Segata N, Shaffer M, Shiffer A, Sinha R, Song SJ, Spear JR, Swafford AD, Thompson LR, Torres PJ, Trinh P, Tripathi A, Turnbaugh PJ, Ul-Hasan S, van der Hooft JJJ, Vargas F, Vázquez-Baeza Y, Vogtmann E, von Hippel M, Walters W, Wan Y, Wang M, Warren J, Weber KC, Williamson CHD, Willis AD, Xu ZZ, Zaneveld JR, Zhang Y, Zhu Q, Knight R, and Caporaso JG. 2019. Reproducible, interactive, scalable and extensible microbiome data science using QIIME 2. Nature Biotechnology 37:852-857. 10.1038/s41587-019-0209-9

Bouter KE, van Raalte DH, Groen AK, and Nieuwdorp M. 2017. Role of the Gut Microbiome in the Pathogenesis of Obesity and Obesity-Related Metabolic Dysfunction. Gastroenterology 152:1671-1678. https://doi.org/10.1053/j.gastro.2016.12.048

Bravo JA, Forsythe P, Chew MV, Escaravage E, Savignac HM, Dinan TG, Bienenstock J, and Cryan JF. 2011. Ingestion of Lactobacillus strain regulates emotional behavior and central GABA receptor expression in a mouse via the vagus nerve. Proceedings of the National Academy of Sciences of the United States of America 108:16050-16055. 10.1073/pnas.1102999108

Brown AS, Schaefer CA, Wyatt RJ, Begg MD, Goetz R, Bresnahan MA, Harkavy-Friedman J, Gorman JM, Malaspina D, and Susser ES. 2002. Paternal age and risk of schizophrenia in adult offspring. The American journal of psychiatry 159:1528-1533. 10.1176/appi.ajp.159.9.1528

Callahan BJ, McMurdie PJ, Rosen MJ, Han AW, Johnson AJ, and Holmes SP. 2016. DADA2: High-resolution sample inference from Illumina amplicon data. Nat Methods 13:581-583. 10.1038/nmeth.3869

Cannon M, Jones PB, and Murray RM. Obstetric Complications and Schizophrenia: Historical and Meta-Analytic Review. American Journal of Psychiatry 159:1080-1092.

Cantor-Graae E, and Selten J-P. 2005. Schizophrenia and Migration: A Meta-Analysis and Review. American Journal of Psychiatry 162:12-24. 10.1176/appi.ajp.162.1.12

Cao B, Wang D, Brietzke E, McIntyre RS, Pan Z, Cha D, Rosenblat JD, Zuckerman H, Liu Y, Xie Q, and Wang JJAA. 2018. Characterizing amino-acid biosignatures amongst individuals with schizophrenia: a casecontrol study. 50:1013-1023. 10.1007/s00726-018-2579-6

Cao H, Pradhan AK, Karns JS, Wolfgang DR, Hovingh E, Vinyard BT, and Van Kessel JAS. 2017. 266 Prevalence and risk factors for antimicrobial resistance on U.S. dairy operations. Journal of Animal Science 95:131-132. $10.2527 /$ asasann.2017.266

Caputi V, and Giron MC. 2018. Microbiome-Gut-Brain Axis and Toll-Like Receptors in Parkinson's Disease. International journal of molecular sciences 19:1689. 10.3390/ijms19061689

Castro-Nallar E, Bendall ML, Pérez-Losada M, Sabuncyan S, Severance EG, Dickerson FB, Schroeder JR, Yolken RH, and Crandall KA. 2015. Composition, taxonomy and functional diversity of the oropharynx microbiome in individuals with schizophrenia and controls. PeerJ 3:e1140-e1140. 10.7717/peerj.1140

Cattaneo A, Cattane N, Galluzzi S, Provasi S, Lopizzo N, Festari C, Ferrari C, Guerra UP, Paghera B, Muscio C, Bianchetti A, Volta GD, Turla M, Cotelli MS, Gennuso M, Prelle A, Zanetti O, Lussignoli G, Mirabile D, Bellandi D, Gentile S, Belotti G, Villani D, Harach T, Bolmont T, Padovani A, Boccardi M, and Frisoni GB. 2017. Association of brain amyloidosis with pro-inflammatory gut bacterial taxa and peripheral inflammation 
438

439

440

441

442

443

444

445

446

447

448

449

450

451

452

453

454

455

456

457

458

459

460

461

462

463

464

465

466

467

468

469

470

471

472

473

474

475

476

477

478

markers in cognitively impaired elderly. Neurobiology of Aging 49:60-68. https://doi.org/10.1016/j.neurobiolaging.2016.08.019

Chintoh AF, Mann SW, Lam L, Giacca A, Fletcher P, Nobrega J, and Remington G. 2009. Insulin resistance and secretion in vivo: effects of different antipsychotics in an animal model. Schizophr Res 108:127-133. 10.1016/j.schres.2008.12.012

Cryan JF, and Dinan TG. 2012. Mind-altering microorganisms: the impact of the gut microbiota on brain and behaviour. Nature Reviews Neuroscience 13:701-712. 10.1038/nrn3346

De Filippo C, Cavalieri D, Di Paola M, Ramazzotti M, Poullet JB, Massart S, Collini S, Pieraccini G, and Lionetti P. 2010. Impact of diet in shaping gut microbiota revealed by a comparative study in children from Europe and rural Africa. Proc Natl Acad Sci U S A 107:14691-14696. 10.1073/pnas.1005963107

De Hert M, Vancampfort D, Correll CU, Mercken V, Peuskens J, Sweers K, van Winkel R, and Mitchell AJ. 2011. Guidelines for screening and monitoring of cardiometabolic risk in schizophrenia: systematic evaluation. $\mathrm{Br}$ J Psychiatry 199:99-105. 10.1192/bjp.bp.110.084665

De Vadder F, Kovatcheva-Datchary P, Goncalves D, Vinera J, Zitoun C, Duchampt A, Bäckhed F, and Mithieux G. 2014. Microbiota-Generated Metabolites Promote Metabolic Benefits via Gut-Brain Neural Circuits. Cell 156:84-96. https://doi.org/10.1016/j.cell.2013.12.016

DeSantis TZ, Hugenholtz P, Larsen N, Rojas M, Brodie EL, Keller K, Huber T, Dalevi D, Hu P, and Andersen GL. 2006. Greengenes, a Chimera-Checked 16S rRNA Gene Database and Workbench Compatible with ARB. 72:5069-5072. 10.1128/AEM.03006-05 \%J Applied and Environmental Microbiology

Desbonnet L, Clarke G, Shanahan F, Dinan TG, and Cryan JF. 2014. Microbiota is essential for social development in the mouse. Molecular Psychiatry 19:146-148. 10.1038/mp.2013.65

Dodd D, Spitzer MH, Van Treuren W, Merrill BD, Hryckowian AJ, Higginbottom SK, Le A, Cowan TM, Nolan GP, Fischbach MA, and Sonnenburg JL. 2017. A gut bacterial pathway metabolizes aromatic amino acids into nine circulating metabolites. Nature 551:648-652. 10.1038/nature24661

Erny D, Hrabě de Angelis AL, Jaitin D, Wieghofer P, Staszewski O, David E, Keren-Shaul H, Mahlakoiv T, Jakobshagen K, Buch T, Schwierzeck V, Utermöhlen O, Chun E, Garrett WS, McCoy KD, Diefenbach A, Staeheli P, Stecher B, Amit I, and Prinz M. 2015. Host microbiota constantly control maturation and function of microglia in the CNS. Nature neuroscience 18:965-977. 10.1038/nn.4030

Galling B, and Correll CU. 2015. Do antipsychotics increase diabetes risk in children and adolescents? Expert Opin Drug Saf 14:219-241. 10.1517/14740338.2015.979150

Hálfdánarson Ó, Zoëga H, Aagaard L, Bernardo M, Brandt L, Fusté AC, Furu K, Garuoliené K, Hoffmann F, Huybrechts KF, Kalverdijk LJ, Kawakami K, Kieler H, Kinoshita T, Litchfield M, López SC, Machado-Alba JE, Machado-Duque ME, Mahesri M, Nishtala PS, Pearson SA, Reutfors J, Saastamoinen LK, Sato I, Schuiling-Veninga CCM, Shyu YC, Skurtveit S, Verdoux H, Wang LJ, Yahni CZ, and Bachmann CJ. 2017. International trends in antipsychotic use: A study in 16 countries, 2005-2014. Eur Neuropsychopharmacol 27:1064-1076. 10.1016/j.euroneuro.2017.07.001

Hartstra AV, Bouter KEC, Bäckhed F, and Nieuwdorp M. 2015. Insights Into the Role of the Microbiome in Obesity and Type 2 Diabetes. Diabetes Care 38:159. 10.2337/dc14-0769

He Y, Kosciolek T, Tang J, Zhou Y, Li Z, Ma X, Zhu Q, Yuan N, Yuan L, and Li CJEP. 2018. Gut microbiome and magnetic resonance spectroscopy study of subjects at ultra-high risk for psychosis may support the membrane hypothesis. 53:37-45.

Peerj reviewing PDF | (2020:02:46023:1:2:NEW 8 Jun 2020) 
Higuchi T, Iyo M, Kwon JS, Chou Y-H, Chen H-K, Chen J-Y, Chen T-T, Huang S-Y, Lee J-S, Saeki Y, Tanaka H, Wang T-S, Wu B-J, Katoh T, and Ishigouoka J. 2019. Randomized, double-blind, placebo, and risperidonecontrolled study of lurasidone in the treatment of schizophrenia: Results of an inconclusive 6-week trial. Asia-Pacific Psychiatry 11:e12354. 10.1111/appy.12354

Hoekert M, Kahn RS, Pijnenborg M, and Aleman A. 2007. Impaired recognition and expression of emotional prosody in schizophrenia: Review and meta-analysis. Schizophrenia Research 96:135-145. https://doi.org/10.1016/j.schres.2007.07.023

Hsiao EY, McBride SW, Hsien S, Sharon G, Hyde ER, McCue T, Codelli JA, Chow J, Reisman SE, Petrosino JF, Patterson PH, and Mazmanian SK. 2013. Microbiota modulate behavioral and physiological abnormalities associated with neurodevelopmental disorders. Cell 155:1451-1463. 10.1016/j.cell.2013.11.024

Hu S, Li A, Huang T, Lai J, Li J, Sublette ME, Lu H, Lu Q, Du Y, Hu Z, Ng CH, Zhang H, Lu J, Mou T, Lu S, Wang D, Duan J, Hu J, Huang M, Wei N, Zhou W, Ruan L, Li MD, and Xu Y. 2019. Gut Microbiota Changes in Patients with Bipolar Depression. Advanced Science 6:1900752. 10.1002/advs.201900752

Huttenhower C, Gevers D, Knight R, Abubucker S, Badger JH, Chinwalla AT, Creasy HH, Earl AM, FitzGerald MG, Fulton RS, Giglio MG, Hallsworth-Pepin K, Lobos EA, Madupu R, Magrini V, Martin JC, Mitreva M, Muzny DM, Sodergren EJ, Versalovic J, Wollam AM, Worley KC, Wortman JR, Young SK, Zeng Q, Aagaard KM, Abolude OO, Allen-Vercoe E, Alm EJ, Alvarado L, Andersen GL, Anderson S, Appelbaum E, Arachchi HM, Armitage G, Arze CA, Ayvaz T, Baker CC, Begg L, Belachew T, Bhonagiri V, Bihan M, Blaser MJ, Bloom T, Bonazzi V, Paul Brooks J, Buck GA, Buhay CJ, Busam DA, Campbell JL, Canon SR, Cantarel BL, Chain PSG, Chen IMA, Chen L, Chhibba S, Chu K, Ciulla DM, Clemente JC, Clifton SW, Conlan S, Crabtree J, Cutting MA, Davidovics NJ, Davis CC, DeSantis TZ, Deal C, Delehaunty KD, Dewhirst FE, Deych E, Ding Y, Dooling DJ, Dugan SP, Michael Dunne W, Scott Durkin A, Edgar RC, Erlich RL, Farmer CN, Farrell RM, Faust K, Feldgarden M, Felix VM, Fisher S, Fodor AA, Forney LJ, Foster L, Di Francesco V, Friedman J, Friedrich DC, Fronick CC, Fulton LL, Gao H, Garcia N, Giannoukos G, Giblin C, Giovanni MY, Goldberg JM, Goll J, Gonzalez A, Griggs A, Gujja S, Kinder Haake S, Haas BJ, Hamilton HA, Harris EL, Hepburn TA, Herter B, Hoffmann DE, Holder ME, Howarth C, Huang KH, Huse SM, Izard J, Jansson JK, Jiang H, Jordan C, Joshi V, Katancik JA, Keitel WA, Kelley ST, Kells C, King NB, Knights D, Kong HH, Koren O, Koren S, Kota KC, Kovar CL, Kyrpides NC, La Rosa PS, Lee SL, Lemon KP, Lennon N, Lewis CM, Lewis L, Ley RE, Li K, Liolios K, Liu B, Liu Y, Lo C-C, Lozupone CA, Dwayne Lunsford R, Madden T, Mahurkar AA, Mannon PJ, Mardis ER, Markowitz VM, Mavromatis K, McCorrison JM, McDonald D, McEwen J, McGuire AL, McInnes P, Mehta T, Mihindukulasuriya KA, Miller JR, Minx PJ, Newsham I, Nusbaum C, O’Laughlin M, Orvis J, Pagani I, Palaniappan K, Patel SM, Pearson M, Peterson J, Podar M, Pohl C, Pollard KS, Pop M, Priest ME, Proctor LM, Qin X, Raes J, Ravel J, Reid JG, Rho M, Rhodes R, Riehle KP, Rivera MC, Rodriguez-Mueller B, Rogers Y-H, Ross MC, Russ C, Sanka RK, Sankar P, Fah Sathirapongsasuti J, Schloss JA, Schloss PD, Schmidt TM, Scholz M, Schriml L, Schubert AM, Segata N, Segre JA, Shannon WD, Sharp RR, Sharpton TJ, Shenoy N, Sheth NU, Simone GA, Singh I, Smillie CS, Sobel JD, Sommer DD, Spicer P, Sutton GG, Sykes SM, Tabbaa DG, Thiagarajan M, Tomlinson CM, Torralba M, Treangen TJ, Truty RM, Vishnivetskaya TA, Walker J, Wang L, Wang Z, Ward DV, Warren W, Watson MA, Wellington C, Wetterstrand KA, White JR, Wilczek-Boney K, Wu Y, Wylie KM, Wylie T, Yandava C, Ye L, Ye Y, Yooseph S, Youmans BP, Zhang L, Zhou Y, Zhu Y, Zoloth L, Zucker JD, Birren BW, Gibbs RA, Highlander SK, Methé BA, Nelson KE, Petrosino JF, Weinstock GM, Wilson RK, White O, 
and The Human Microbiome Project C. 2012. Structure, function and diversity of the healthy human microbiome. Nature 486:207-214. 10.1038/nature11234

Huttenhower C, Kostic AD, and Xavier RJ. 2014. Inflammatory bowel disease as a model for translating the microbiome. Immunity 40:843-854. 10.1016/j.immuni.2014.05.013

Kao AC, Spitzer S, Anthony DC, Lennox B, and Burnet PWJ. 2018. Prebiotic attenuation of olanzapine-induced weight gain in rats: analysis of central and peripheral biomarkers and gut microbiota. Transl Psychiatry 8:66. 10.1038/s41398-018-0116-8

Kelly JR, Minuto C, Cryan JF, Clarke G, and Dinan TG. 2017. Cross Talk: The Microbiota and Neurodevelopmental Disorders. Frontiers in neuroscience 11:490-490. 10.3389/fnins.2017.00490

Kraus JE, Sheitman BB, Cook A, Reviere R, and Lieberman JA. 2006. Olanzapine Versus Risperidone in Newly Admitted Acutely Ill Psychotic Patients. Journal of Clinical Psychiatry 66:1564-1568.

Langille MGI, Zaneveld J, Caporaso JG, McDonald D, Knights D, Reyes JA, Clemente JC, Burkepile DE, Vega Thurber RL, Knight R, Beiko RG, and Huttenhower C. 2013. Predictive functional profiling of microbial communities using 16S rRNA marker gene sequences. Nature Biotechnology 31:814. 10.1038/nbt.2676

https://www.nature.com/articles/nbt.2676\#supplementary-information

Louveau A, Herz J, Alme MN, Salvador AF, Dong MQ, Viar KE, Herod SG, Knopp J, Setliff JC, Lupi AL, Da Mesquita S, Frost EL, Gaultier A, Harris TH, Cao R, Hu S, Lukens JR, Smirnov I, Overall CC, Oliver G, and Kipnis J. 2018. CNS lymphatic drainage and neuroinflammation are regulated by meningeal lymphatic vasculature. Nature neuroscience 21:1380-1391. 10.1038/s41593-018-0227-9

Lv F, Chen S, Wang L, Jiang R, Tian H, Li J, Yao Y, and Zhuo C. The role of microbiota in the pathogenesis of schizophrenia and major depressive disorder and the possibility of targeting microbiota as a treatment option. Oncotarget 8.

McGlashan TH, and Fenton WS. 1992. The Positive-Negative Distinction in Schizophrenia - Review of NaturalHistory Validators. Arch Gen Psychiatry 49:63-72.

Morgan AP, Crowley JJ, Nonneman RJ, Quackenbush CR, Miller CN, Ryan AK, Bogue MA, Paredes SH, Yourstone S, Carroll IM, Kawula TH, Bower MA, Sartor RB, and Sullivan PF. 2014. The antipsychotic olanzapine interacts with the gut microbiome to cause weight gain in mouse. PLoS One 9:e115225. 10.1371/journal.pone.0115225

Morris G, Berk M, Carvalho A, Caso JR, Sanz Y, Walder K, and Maes M. 2017. The Role of the Microbial Metabolites Including Tryptophan Catabolites and Short Chain Fatty Acids in the Pathophysiology of ImmuneInflammatory and Neuroimmune Disease. Molecular Neurobiology 54:4432-4451. 10.1007/s12035-0160004-2

Mudd AT, Berding K, Wang M, Donovan SM, and Dilger RN. 2017. Serum cortisol mediates the relationship between fecal Ruminococcus and brain N-acetylaspartate in the young pig. Gut microbes 8:589-600. 10.1080/19490976.2017.1353849

Mulvany F, O'Callaghan E, Takei N, Byrne M, Fearon P, and Larkin C. 2001. Effect of social class at birth on risk and presentation of schizophrenia: case-control study. BMJ (Clinical research ed) 323:1398-1401. 10.1136/bmj.323.7326.1398

Nam Y-D, Jung M-J, Roh SW, Kim M-S, and Bae J-W. 2011. Comparative analysis of Korean human gut microbiota by barcoded pyrosequencing. PLoS One 6:e22109-e22109. 10.1371/journal.pone.0022109

Nguyen TT, Kosciolek T, Eyler LT, Knight R, and Jeste DV. 2018. Overview and systematic review of studies of 
microbiome in schizophrenia and bipolar disorder. Journal of psychiatric research 99:50-61. 10.1016/j.jpsychires.2018.01.013

Ogata H, Goto S, Sato K, Fujibuchi W, Bono H, and Kanehisa M. 2000. KEGG: Kyoto Encyclopedia of Genes and Genomes. Nucleic Acids Research 27:29-34.

Oksanen J, Blanchet FG, Friendly M, Kindt R, Legendre P, McGlinn D, Minchin PR, O'Hara R, Simpson GL, and Solymos P. 2019. Package 'vegan'.

Pełka-Wysiecka J, Kaczmarczyk M, Bąba-Kubiś A, Liśkiewicz P, Wroński M, Skonieczna-Żydecka K, Marlicz W, Misiak B, Starzyńska T, Kucharska-Mazur J, Łoniewski I, and Samochowiec J. 2019. Analysis of Gut Microbiota and Their Metabolic Potential in Patients with Schizophrenia Treated with Olanzapine: Results from a Six-Week Observational Prospective Cohort Study. Journal of clinical medicine 8:1605. $10.3390 / \mathrm{jcm} 8101605$

Ripke S, Sanders AR, Kendler KS, Levinson DF, Sklar P, Holmans PA, Lin D-Y, Duan J, Ophoff RA, Andreassen OA, Scolnick E, Cichon S, St. Clair D, Corvin A, Gurling H, Werge T, Rujescu D, Blackwood DHR, Pato CN, Malhotra AK, Purcell S, Dudbridge F, Neale BM, Rossin L, Visscher PM, Posthuma D, Ruderfer DM, Fanous A, Stefansson H, Steinberg S, Mowry BJ, Golimbet V, De Hert M, Jönsson EG, Bitter I, Pietiläinen OPH, Collier DA, Tosato S, Agartz I, Albus M, Alexander M, Amdur RL, Amin F, Bass N, Bergen SE, Black DW, Børglum AD, Brown MA, Bruggeman R, Buccola NG, Byerley WF, Cahn W, Cantor RM, Carr VJ, Catts SV, Choudhury K, Cloninger CR, Cormican P, Craddock N, Danoy PA, Datta S, de Haan L, Demontis D, Dikeos D, Djurovic S, Donnelly P, Donohoe G, Duong L, Dwyer S, Fink-Jensen A, Freedman R, Freimer NB, Friedl M, Georgieva L, Giegling I, Gill M, Glenthøj B, Godard S, Hamshere M, Hansen M, Hansen T, Hartmann AM, Henskens FA, Hougaard DM, Hultman CM, Ingason A, Jablensky AV, Jakobsen KD, Jay M, Jürgens G, Kahn RS, Keller MC, Kenis G, Kenny E, Kim Y, Kirov GK, Konnerth H, Konte B, Krabbendam L, Krasucki R, Lasseter VK, Laurent C, Lawrence J, Lencz T, Lerer FB, Liang K-Y, Lichtenstein P, Lieberman JA, Linszen DH, Lönnqvist J, Loughland CM, Maclean AW, Maher BS, Maier W, Mallet J, Malloy P, Mattheisen M, Mattingsdal M, McGhee KA, McGrath JJ, McIntosh A, McLean DE, McQuillin A, Melle I, Michie PT, Milanova V, Morris DW, Mors O, Mortensen PB, Moskvina V, Muglia P, Myin-Germeys I, Nertney DA, Nestadt G, Nielsen J, Nikolov I, Nordentoft M, Norton N, Nöthen MM, O'Dushlaine CT, Olincy A, Olsen L, O'Neill FA, Ørntoft TF, Owen MJ, Pantelis C, Papadimitriou G, Pato MT, Peltonen L, Petursson H, Pickard B, Pimm J, Pulver AE, Puri V, Quested D, Quinn EM, Rasmussen HB, Réthelyi JM, Ribble R, Rietschel M, Riley BP, Ruggeri M, Schall U, Schulze TG, Schwab SG, Scott RJ, Shi J, Sigurdsson E, Silverman JM, Spencer CCA, Stefansson K, Strange A, Strengman E, Stroup TS, Suvisaari J, Terenius L, Thirumalai S, Thygesen JH, Timm S, Toncheva D, van den Oord E, van Os J, van Winkel R, Veldink J, Walsh D, Wang AG, Wiersma D, Wildenauer DB, Williams HJ, Williams NM, Wormley B, Zammit S, Sullivan PF, O'Donovan MC, Daly MJ, Gejman PV, and The Schizophrenia Psychiatric Genome-Wide Association Study C. 2011. Genome-wide association study identifies five new schizophrenia loci. Nature Genetics 43:969-976. 10.1038/ng.940

Saleem S, Shaukat F, Gul A, Arooj M, and Malik A. 2017. Potential role of amino acids in pathogenesis of schizophrenia. International journal of health sciences 11:63-68.

Sampson TR, Debelius JW, Thron T, Janssen S, Shastri GG, Ilhan ZE, Challis C, Schretter CE, Rocha S, Gradinaru V, Chesselet M-F, Keshavarzian A, Shannon KM, Krajmalnik-Brown R, Wittung-Stafshede P, Knight R, and Mazmanian SK. 2016. Gut Microbiota Regulate Motor Deficits and Neuroinflammation in a Model of 
602

603

604

605

606

607

608

609

610

611

612

613

614

615

616

617

618

619

620

621

622

623

624

625

626

627

628

629

630

631

632

633

634

635

636

637

638

639

640

641

642

Parkinson's Disease. Cell 167:1469-1480.e1412. 10.1016/j.cell.2016.11.018

Sara GE, Large MM, Matheson SL, Burgess PM, Malhi GS, Whiteford HA, and Hall WD. 2014. Stimulant use disorders in people with psychosis: A meta-analysis of rate and factors affecting variation. Australian \& New Zealand Journal of Psychiatry 49:106-117. 10.1177/0004867414561526

Schwabe RF, and Jobin C. 2013. The microbiome and cancer. Nature reviews Cancer 13:800-812. 10.1038/nrc3610

Schwarz E, Maukonen J, Hyytiäinen T, Kieseppä T, Orešič M, Sabunciyan S, Mantere O, Saarela M, Yolken R, and Suvisaari J. 2018. Analysis of microbiota in first episode psychosis identifies preliminary associations with symptom severity and treatment response. Schizophrenia Research 192:398-403. https://doi.org/10.1016/j.schres.2017.04.017

Severance EG, Alaedini A, Yang S, Halling M, Gressitt KL, Stallings CR, Origoni AE, Vaughan C, Khushalani S, Leweke FM, Dickerson FB, and Yolken RH. 2012. Gastrointestinal inflammation and associated immune activation in schizophrenia. Schizophrenia Research 138:48-53. 10.1016/j.schres.2012.02.025

Severance EG, Prandovszky E, Castiglione J, and Yolken RH. 2015. Gastroenterology issues in schizophrenia: why the gut matters. Current psychiatry reports 17:27-27. 10.1007/s11920-015-0574-0

Shen Y, Xu J, Li Z, Huang Y, Yuan Y, Wang J, Zhang M, Hu S, and Liang Y. 2018. Analysis of gut microbiota diversity and auxiliary diagnosis as a biomarker in patients with schizophrenia: A cross-sectional study. Schizophrenia Research 197:470-477. https://doi.org/10.1016/j.schres.2018.01.002

Sherwin E, Sandhu KV, Dinan TG, and Cryan JF. 2016. May the Force Be With You: The Light and Dark Sides of the Microbiota-Gut-Brain Axis in Neuropsychiatry. CNS drugs 30:1019-1041. 10.1007/s40263-016-0370-3

Shukla SD, Budden KF, Neal R, and Hansbro PM. 2017. Microbiome effects on immunity, health and disease in the lung. Clinical \& translational immunology 6:e133-e133. 10.1038/cti.2017.6

Skonieczna-Żydecka K, Łoniewski I, Misera A, Stachowska E, Maciejewska D, Marlicz W, and Galling B. 2019. Second-generation antipsychotics and metabolism alterations: a systematic review of the role of the gut microbiome. Psychopharmacology 236:1491-1512. 10.1007/s00213-018-5102-6

Stilo SA, Gayer-Anderson C, Beards S, Hubbard K, Onyejiaka A, Keraite A, Borges S, Mondelli V, Dazzan P, Pariante C, Di Forti M, Murray RM, and Morgan C. 2017. Further evidence of a cumulative effect of social disadvantage on risk of psychosis. Psychological medicine 47:913-924. 10.1017/S0033291716002993

Tan J, McKenzie C, Potamitis M, Thorburn AN, Mackay CR, and Macia L. 2014. Chapter Three - The Role of ShortChain Fatty Acids in Health and Disease. In: Alt FW, ed. Advances in Immunology: Academic Press, 91-119.

Tomova A, Husarova V, Lakatosova S, Bakos J, Vlkova B, Babinska K, and Ostatnikova D. 2015. Gastrointestinal microbiota in children with autism in Slovakia. Physiology \& Behavior 138:179-187. https://doi.org/10.1016/j.physbeh.2014.10.033

van Os J, Pedersen CB, and Mortensen PB. 2004. Confirmation of Synergy Between Urbanicity and Familial Liability in the Causation of Psychosis. American Journal of Psychiatry 161:2312-2314. 10.1176/appi.ajp.161.12.2312

Varese F, Smeets F, Drukker M, Lieverse R, Lataster T, Viechtbauer W, Read J, van Os J, and Bentall RP. 2012. Childhood adversities increase the risk of psychosis: a meta-analysis of patient-control, prospective- and cross-sectional cohort studies. Schizophrenia bulletin 38:661-671. 10.1093/schbul/sbs050

Wang H, Geier MS, and Howarth GS. 2016. Prebiotics: A Potential Treatment Strategy for the Chemotherapydamaged Gut? Critical Reviews in Food Science and Nutrition 56:946-956. 10.1080/10408398.2012.741082

Wong JMW, de Souza R, Kendall CWC, Emam A, and Jenkins DJA. 2006. Colonic Health: Fermentation and Short 
643

644

645

646

647

648

649

650

651

652

653

654

655

656

657

658

659

660

661

662

663

664

665

666

667

668

669

670

671

672

673

674

675

Chain Fatty Acids. 40:235-243.

Wu F, Zhang Y, Yang Y, Lu X, Fang Z, Huang J, Kong L, Chen J, Ning Y, Li X, and Wu K. 2018. Structural and functional brain abnormalities in drug-naive, first-episode, and chronic patients with schizophrenia: a multimodal MRI study. Neuropsychiatric disease and treatment 14:2889-2904. 10.2147/NDT.S174356

Wu Y, Bi R, Zeng C, Ma C, Sun C, Li J, Xiao X, Li M, Zhang D-F, Zheng P, Sheng N, Luo X-J, and Yao Y-G. 2019. Identification of the primate-specific gene BTN3A2 as an additional schizophrenia risk gene in the MHC loci. EBioMedicine 44:530-541. 10.1016/j.ebiom.2019.05.006

Yee TW. 2007. VGAM: Vector Generalized Linear and Additive Models.

Yolken RH, Severance EG, Sabunciyan S, Gressitt KL, Chen O, Stallings C, Origoni A, Katsafanas E, Schweinfurth LAB, Savage CLG, Banis M, Khushalani S, and Dickerson FB. 2015. Metagenomic Sequencing Indicates That the Oropharyngeal Phageome of Individuals With Schizophrenia Differs From That of Controls. Schizophrenia bulletin 41:1153-1161. 10.1093/schbul/sbu197

Yuan X, Kang Y, Zhuo C, Huang X-F, and Song X. 2019. The gut microbiota promotes the pathogenesis of schizophrenia via multiple pathways. Biochemical and Biophysical Research Communications 512:373-380. https://doi.org/10.1016/j.bbrc.2019.02.152

Zhang J, Guo Z, Xue Z, Sun Z, Zhang M, Wang L, Wang G, Wang F, Xu J, Cao H, Xu H, Lv Q, Zhong Z, Chen Y, Qimuge S, Menghe B, Zheng Y, Zhao L, Chen W, and Zhang H. 2015. A phylo-functional core of gut microbiota in healthy young Chinese cohorts across lifestyles, geography and ethnicities. The ISME journal 9:1979-1990. 10.1038/ismej.2015.11

Zheng P, Zeng B, Liu M, Chen J, Pan J, Han Y, Liu Y, Cheng K, Zhou C, Wang H, Zhou X, Gui S, Perry SW, Wong M-L, Licinio J, Wei H, and Xie P. 2019. The gut microbiome from patients with schizophrenia modulates the glutamate-glutamine-GABA cycle and schizophrenia-relevant behaviors in mice. Science Advances 5:eaau8317. 10.1126/sciadv.aau8317

Zheng P, Zeng B, Zhou C, Liu M, Fang Z, Xu X, Zeng L, Chen J, Fan S, Du X, Zhang X, Yang D, Yang Y, Meng H, Li W, Melgiri ND, Licinio J, Wei H, and Xie P. 2016. Gut microbiome remodeling induces depressive-like behaviors through a pathway mediated by the host's metabolism. Molecular Psychiatry 21:786-796. 10.1038/mp.2016.44

Zhu F, Guo R, Wang W, Ju Y, Wang Q, Ma Q, Sun Q, Fan Y, Xie Y, Yang Z, Jie Z, Zhao B, Xiao L, Yang L, Zhang T, Liu B, Guo L, He X, Chen Y, Chen C, Gao C, Xu X, Yang H, Wang J, Dang Y, Madsen L, Brix S, Kristiansen K, Jia H, and Ma X. 2019. Transplantation of microbiota from drug-free patients with schizophrenia causes schizophrenia-like abnormal behaviors and dysregulated kynurenine metabolism in mice. Mol Psychiatry. 10.1038/s41380-019-0475-4

Peer) reviewing PDF | (2020:02:46023:1:2:NEW 8 Jun 2020) 


\section{Table $\mathbf{1}$ (on next page)}

Demographic characteristic of schizophrenia and normal controls. Values are shown as mean \pm SD or ratio.

$\mathrm{BMI}=$ body mass index; S-HDL-C = serum high-density lipoprotein cholesterol; S-LDL-C = serum low-density lipoprotein cholesterol; S-Glu = serum glucose. "*” 8 NCs and 10 SZ patients lacked BMI information. 
1 Table 1 Demographic characteristic of schizophrenia and normal controls. Values are shown as 2 mean $\pm \mathrm{SD}$ or ratio.

\begin{tabular}{llll}
\hline Characteristic & NC group $(\mathrm{n}=80)$ & SZ group $(\mathrm{n}=82)$ & p-value \\
\hline Age & $41.03 \pm 14.34$ & $42.15 \pm 13.13$ & 0.60 \\
Sex $(\mathrm{M} / \mathrm{F})$ & $39 / 41$ & $46 / 36$ & 0.35 \\
BMI $\left(\mathrm{kg} / \mathrm{m}^{2}\right) *$ & $23.03 \pm 3.05$ & $24.48 \pm 4.33$ & 0.01 \\
PANSS & - & $59.12 \pm 18.18$ & - \\
Education year & $13.95 \pm 3.49$ & $11.22 \pm 3.51$ & $2.04 \times 10^{-6}$ \\
S-HDL-C (mmol/l) & $1.65 \pm 0.29$ & $1.40 \pm 0.50$ & $1.43 \times 10^{-4}$ \\
S-LDL-C (mmol/1) & $3.62 \pm 0.95$ & $2.97 \pm 0.84$ & $7.95 \times 10^{-6}$ \\
S-Glu $(\mathrm{mmol} / \mathrm{l})$ & $5.77 \pm 1.15$ & $4.83 \pm 1.04$ & $1.38 \times 10^{-8}$ \\
TC $(\mathrm{mmol} / \mathrm{l})$ & $6.24 \pm 1.19$ & $4.76 \pm 0.94$ & $4.59 \times 10^{-15}$ \\
TG $(\mathrm{mmol} / \mathrm{l})$ & $1.26 \pm 0.69$ & $1.56 \pm 0.83$ & 0.01 \\
Tobacco intake $(\%)$ & 5 & 20.7 & 0.01 \\
Alcohol intake $(\%)$ & 37.5 & 3.7 & $3.36 \times 10^{-8}$ \\
\hline
\end{tabular}

$3 \mathrm{BMI}=$ body mass index; S-HDL-C = serum high-density lipoprotein cholesterol; S-LDL-C = 4 serum low-density lipoprotein cholesterol; $\mathrm{S}-\mathrm{Glu}=$ serum glucose; $\mathrm{TC}=$ Total Cholesterol; $\mathrm{TG}=$ 5 Triglyceride. "*” 8 NCs and $10 \mathrm{SZ}$ patients lacked BMI information. 
Figure 1

Principal coordinates analysis ( $\mathrm{PCOA}$ ) plot illustrating beta-diversity distance matrices of Bray-Curtis distance comparing sample distributions between the SZ and NC groups.

Red dots and green triangles represent NCs and SZ patients, respectively.

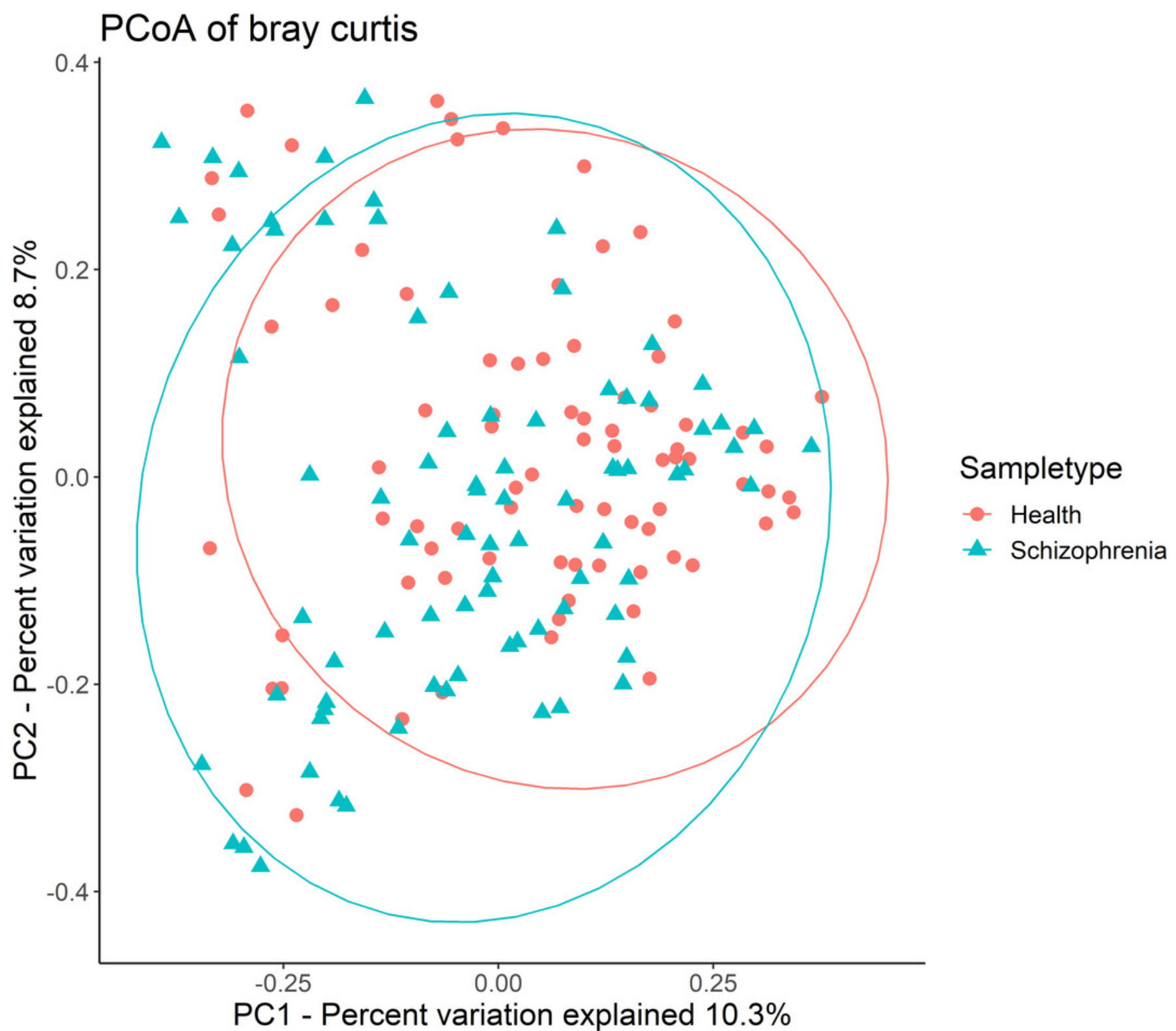




\section{Figure 2}

Microbial composition at phylum and genus levels.

(A-B) indicate the most abundant genera and phyla in the NC and SZ groups, respectively. Bacteria that were significantly different between the two groups are shown in $(A-B)(p<$ 0.05, FDR correction, “ $\uparrow$ " represent higher in SZs and “ $\downarrow$ " represent lower, respectively).
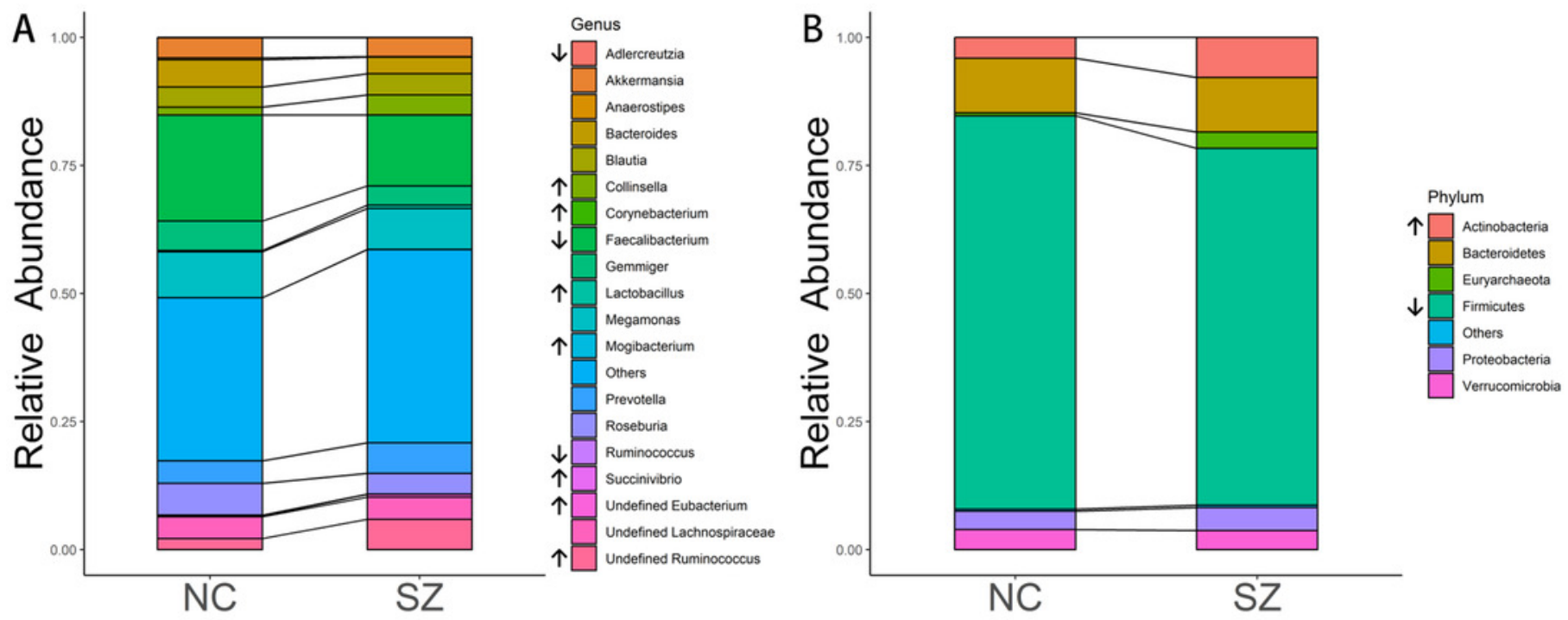
Figure 3

The differently abundant taxa identified using LEfSe analysis.

(A) LEfSe cladogram showed the most differentially abundant taxa between the two groups.

Taxa enriched for NC in red; SZ enriched taxa in green. The size of each dot is proportional to its effect size. (B) Visualization of only taxa meeting an LDA threshold $>2$. Taxa with enriched levels in SZs are shown in green, red represented taxa with enriched levels in NCs.

A

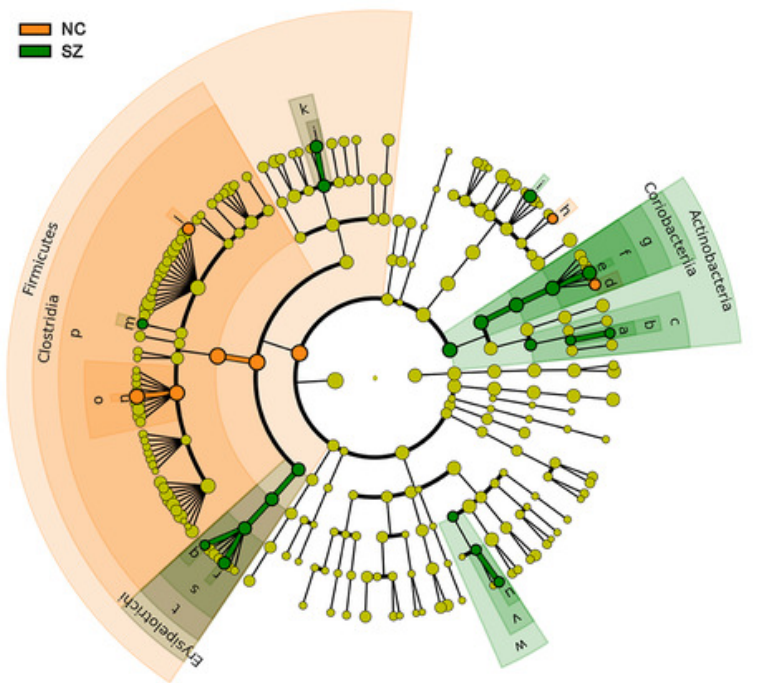

$B \square N C=s z$

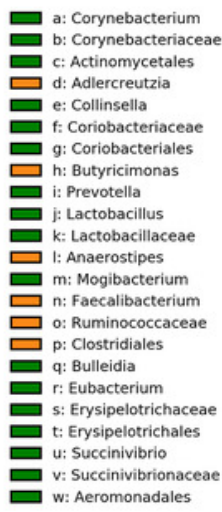

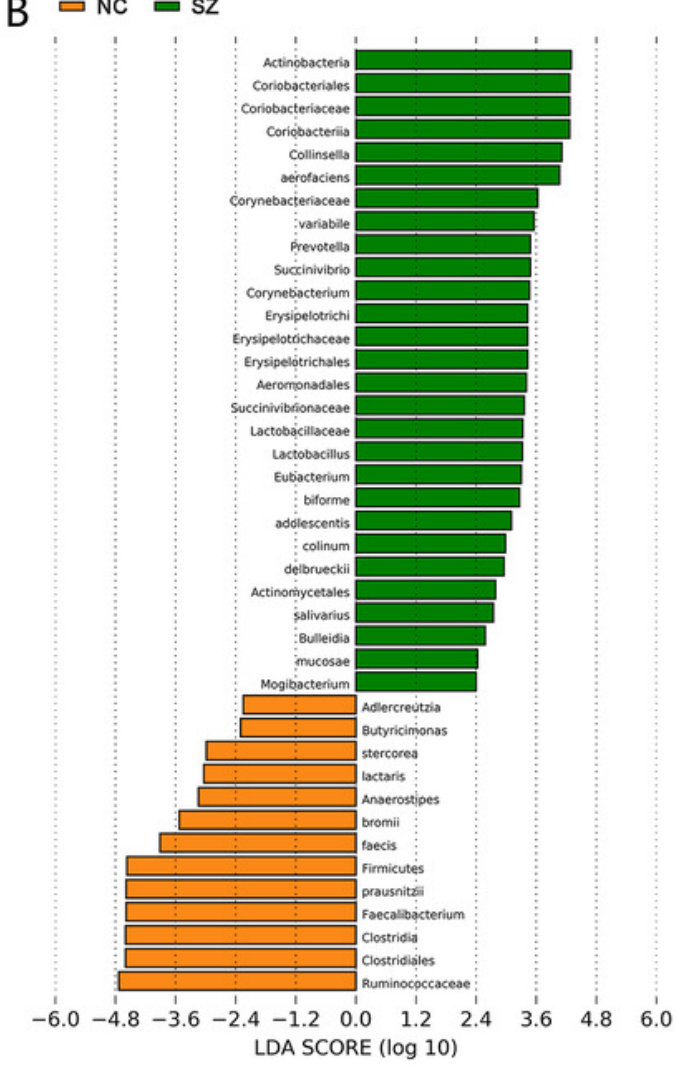




\section{Figure 4}

\section{Functional prediction analysis of two groups using PICRUSt.}

In the figure, the abundance of the biological pathways between the two groups are

statistically significant ( $p<0.05$, FDR corrected). Red and blue represent NC group and SZ

group, respectively.

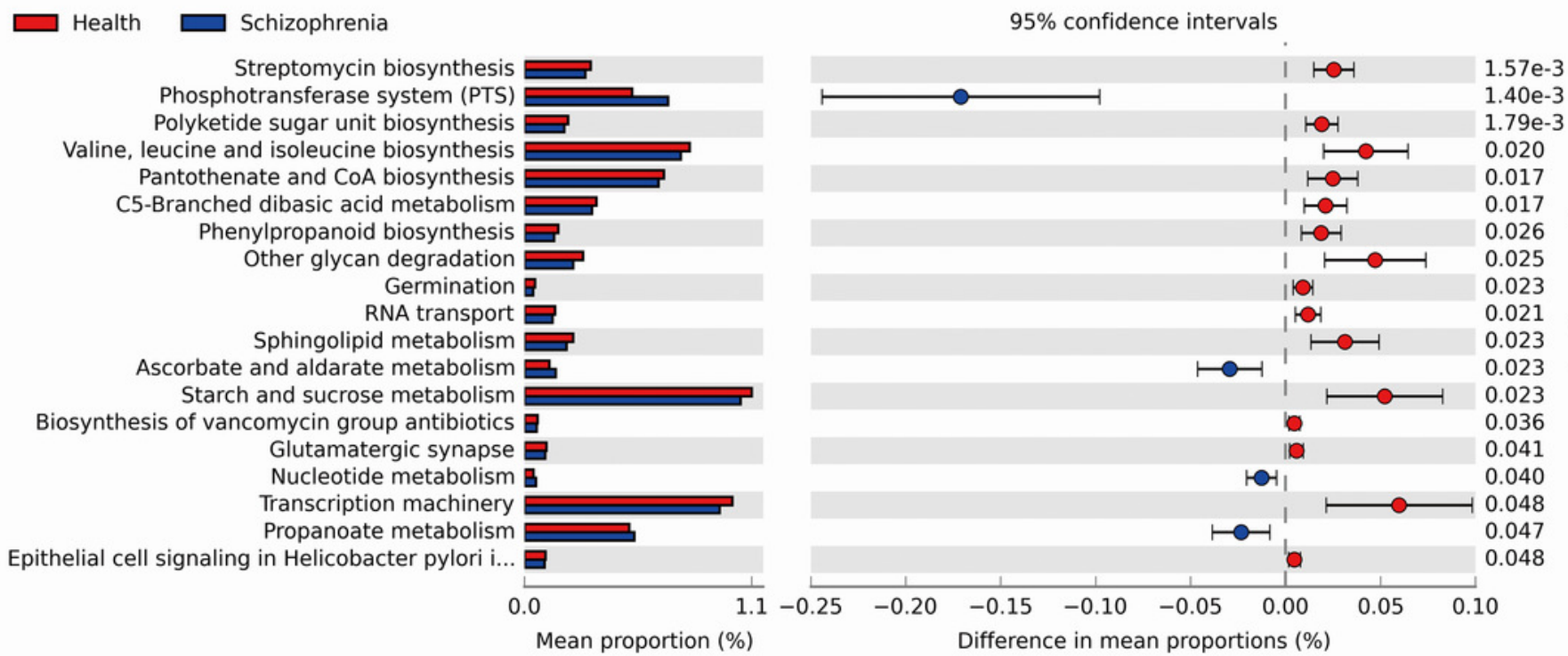




\section{Figure 5}

Correlation between the relative abundances of the alter genera and PANSS scores.

The color bar indicates the value of Pearson correlation's coefficient. And the size of circles indicates the degree of significance. "*": $p<0.05$, uncorrected.

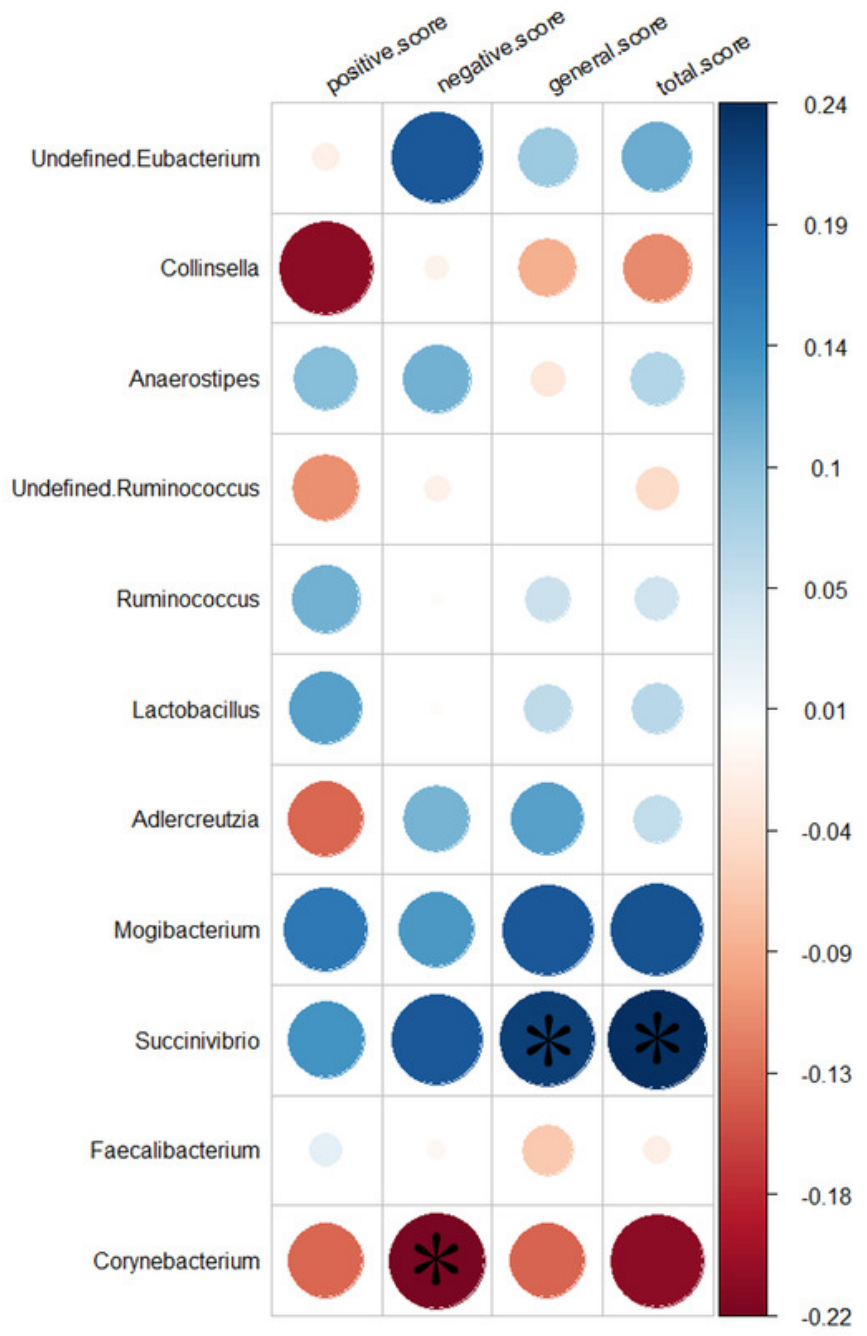

